\title{
Has influence of extratropical waves in modulating Indian summer monsoon rainfall (ISMR) increased?
}

\author{
A K Srivastava*, Somenath Dutta, S R Kshirsagar and Kavita Srivastava \\ India Meteorological Department, Shivajinagar, Pune 411 005, India. \\ ${ }^{*}$ Corresponding author. e-mail: aksrivastava@hotmail.com
}

In the paper, influence of extratropical circulation features on Indian Summer Monsoon Rainfall (ISMR) is examined. Energetics of extratropics, north of Indian subcontinent for deficient and non-deficient ISMR years, during two periods 1951-1978 and 1979-2005, are calculated and critically analyzed. It is observed that for the period 1951-1978, only two out of the 10 energetics parameters, viz., the zonal available potential energy (high) and conversion of zonal kinetic energy to eddy kinetic energy (low) differed significantly in JJA months of the deficient years from that of the non-deficient years. However, during the 1979-2005 period, as many as six out of the 10 energetics parameters, viz., eddy available potential energy, zonal available potential energy, eddy kinetic energy, generation of zonal available potential energy, conversion of zonal available potential energy to zonal kinetic energy and conversion of zonal kinetic energy to eddy kinetic energy differed significantly in JJA months of the deficient years from that of the non-deficient years. These results confirm growing influence of the transient stationary waves in deficient years after the climate shift year, 1979. Analysis of energetics parameters of the premonsoon season of the two periods also reveals similar results. This suggests that forcings apparently responsible for energetics in JJA months of the deficient years of the later period were present even before the advent of Indian summer monsoon season.

\section{Introduction}

Indian summer monsoon circulation features, a large scale tropical phenomenon responsible for Indian Summer Monsoon Rainfall (ISMR), is influenced by all the major modes of climate variability. The El Nino/Southern Oscillation (ENSO) phenomenon, originating in the tropical Pacific Ocean has been reported to significantly influence ISMR by many studies. After Walker (1924) and Bjerknes (1969), observational analyses by Rasmusson and Carpenter (1982) have shown that the planetary scale tropical sea level pressure anomalies, manifested as a see-saw pattern between the Indian and Pacific Oceans, affects the ISMR. Many severe droughts over India occurred, when in association with the El Nino events, sea level pressure anomalies over the Indian Ocean were high and same were low over the most parts of the Pacific Ocean. Subsequently, many studies like Sikka (1980), Pant and Parthasarathy (1981), Keshavamurty (1982), Barnett (1983), Rasmusson and Carpenter (1983), Mooley and Parthasarathy (1984), Webster and Yang (1992), Krishnamurthy and Goswami (2000), Kane (2005), Krishna Kumar et al. (2006), Rajeevan and Pai (2007), examined different aspects of ENSO and Indian summer monsoon relationship. This relationship was found to be robust and stable over a longer period of time. However, the study of Krishna Kumar et al. (1999)

Keywords. Energetics; eddy available potential energy; zonal available potential energy; eddy kinetic energy; zonal kinetic energy. 
reported weakening of this relationship in the past two decades or so.

Extratropical circulation anomalies also affect the ISMR. Initially it was highlighted that appearance and movement of waves (superimposed on mean westerly flow of the extratropics) during monsoon season, cause lull phase (break spell) of the ISMR (Raman and Rao 1981). Subsequently, many studies reported enhanced role of the extratropics in influencing the ISMR. Chang et al. (2001) and Pai (2004) suggested that the weaker linkage between ENSO and the ISMR since 1983 may be due to stronger influence from the North Atlantic Ocean over the Indian monsoon. Kripalani et al. (1997) reported a significant relationship with winter west Pacific oscillation with subsequent summer monsoon rainfall over India on interannual time scale. Srivastava et al. (2002) reported that extratropical circulation anomalies apparently modulated by the north Atlantic oscillations (NAO) influence the ISMR on inter annual scale. Dynamical studies highlight that linkage between the NAO induced circulation features and the ISMR appeared through Rossby wave train emanating from the north Atlantic and propagating along the Asian Jet stream (Hoskins and Ambrizzi 1993; Branstator 2002). Role of the extratropics in modulating the ISMR was highlighted by some more recent studies like Ding and Wang (2005, 2007), Goswami et al. (2006), Srivastava et al. (2007) and Li et al. (2008). Study of Goswami et al. (2006) brings out evidences of influence of north Atlantic SST anomalies on Indian monsoon, especially on mutli-decadal time scale. Srivastava et al. (2007) highlight presence of a quasi-permanent standing wave in the extratropics to north of Indian subcontinent, particularly in the first half of monsoon season during 2002. The study of Ding and Wang $(2005,2007)$ revealed a recurrent Circum Global Tele connection (CGT) pattern in the summer time mid-latitude circulation of the Northern Hemisphere, modulating rainfall and surface air temperature anomalies over India. The study of Li et al. (2008) used atmospheric model simulations and showed that warm extratropical north Atlantic SSTs induce an arching extratropical wave train response, enhancing Indian summer monsoon rainfall. A more recent study by Krishnan et al. (2009) indicated that droughts over India emanate largely from prolonged 'monsoon breaks' that occur on subseasonal time scales and involve dynamical feedbacks between monsoon convection and extratropical circulation anomalies.

It may be seen that almost all studies examining the extratropics and the ISMR indicate interaction between them through the waves emanating in the extratropics due to some or other forcings. However, not many studies have investigated energetics aspect of extratropical circulation features apparently affecting the ISMR. Energetics is a very useful tool to understand atmospheric features dynamically. Dutta et al. (2012) studied energetics for the tropics for contrasting ISMR seasons and found that due to mid-latitude circulation anomalies, mean monsoon circulation was weak during some deficient ISMR years in daily, monthly and seasonal time scale.

In this paper, energetics over the extratropics for deficient and non-deficient ISMR years of the two periods, 1951-1978 and 1979-2005 have been calculated and analyzed to find that influence of extratropical circulation features has increased in the deficient years of the recent period.

\section{Data and methodology}

For computation of energetics parameters, monthly data for $u, \nu, \omega, T$, obtained from NCEP/NCAR have been used. Energetics for deficient and non-deficient years for two periods, 1951-1978 and 1979-2005 are calculated separately. It may be mentioned that when in a year the ISMR (standard deviation of ISMR is around $10 \%$ of its normal value) is below $10 \%$ of its normal value, the year is categorized as the deficient year. There were six and seven deficient years for the periods 1951-1978 and 1979-2005, respectively. These years with rainfall deficiency for the 1951-1978 period are 1951 $(-18.7 \%), 1965(-18.2 \%), 1966(-13.2 \%), 1968$ $(-10.3 \%), 1972(-23.9 \%), 1974(-10.2 \%)$. Same for the 1979-2005 period are $1979(-18.9 \%), 1982$ $(-14.4 \%), 1986(-12.7 \%), 1987(-19.4 \%), 1991$ $(-9.3 \%), 2002(-19.2 \%)$ and $2004(-13.8 \%)$. Selection of the two periods was made, keeping in view that several studies report 'climate shift' around the year 1979 and some major forcings like El-Nino events and NAO have shown distinct changes in its evolution and phase after the climate shift year.

The area bound between latitudes $35^{\circ}-55^{\circ} \mathrm{N}$ and longitudes $40^{\circ}-120^{\circ} \mathrm{E}$, is chosen for computation of the energetics parameters. As transient Rossby waves are generally more prominent in the middle and upper tropospheres, we considered $600 \mathrm{hPa}$ to $200 \mathrm{hPa}$ levels for calculating energetics. All the (10) energetics parameters for each deficient and non-deficient years for the data periods are calculated. We have calculated energetics for March, April and May (MAM - pre-monsoon season) and June, July and August (JJA - monsoon season) months. Subsequently, calculation of energetics for the seasons MAM and JJA was done by simple average of the values of energetics of the MAM and JJA months. Further, Student ' $t$ ' test has been applied to examine significance in difference 
in each of 10 energetics values calculated for deficient and non-deficient years of JJA and MAM seasons for two periods 1951-1978 and 1979-2005, separately. The energetics parameters, in which statistically significant difference between the deficient and non-deficient years was observed, are discussed in detail. The probable reasons for the significant difference are also examined.

\subsection{Calculation of energetics}

First, from the temperature data, at each grid point, heating rate $\dot{Q} / C_{p}$ has been computed using first law of thermodynamics

$$
\frac{\dot{Q}}{C_{p}}=\frac{d T}{d t}-\frac{\alpha}{C_{p}} \omega
$$

In the computation of $d T / d t$, tendency has not been taken care of. Then, following Krishnamurty and Bounoua (2000), zonal average, area average, deviation from the area average, deviation from zonal average and finally the departure of the zonal average from area average of an arbitrary field ' $S$ ' have been computed as below:

Zonal average:

$$
[S]=\frac{1}{\lambda_{e}-\lambda_{w}} \int_{\lambda_{w}}^{\lambda_{e}} S d \lambda
$$

Area average:

$$
\bar{S}=\frac{1}{\sin \varphi_{n}-\sin \varphi_{s}} \int_{\varphi_{s}}^{\varphi_{n}}[S] \cos \varphi d \varphi
$$

Departure from area average:

$$
S^{\prime \prime}=S-\bar{S}
$$

Departure from zonal average:

$$
S^{\prime}=S-[S]
$$

Departure of zonal average from area average:

$$
S^{*}=[S]-\bar{S}
$$

Then using equations (1-5), zonal averages, area averages, departure from zonal and area average and finally zonal eddy components of the above fields, including heating rate, have been computed. Using these averages and zonal eddies and method adopted by Krishnamurty and Bounoua (2000), zonal available potential energy $\left(A_{z}\right)$, zonal kinetic energy $\left(K_{z}\right)$, eddy available potential energy $\left(A_{E}\right)$, eddy kinetic energy $\left(K_{E}\right)$, generation of zonal available potential energy $\left(G\left(A_{z}\right)\right)$, generation of eddy available potential energy $\left(G\left(A_{E}\right)\right)$, conversion of $A_{z}$ to $A_{E}\left(C\left(A_{z}, A_{E}\right)\right)$, conversion of $A_{z}$ to $K_{Z}\left(C\left(A_{z}, K_{z}\right)\right)$, conversion of $A_{E}$ to $K_{E}\left(C\left(A_{E}, K_{E}\right)\right)$ and conversion of $K_{z}$ to $K_{E}\left(C\left(K_{z}, K_{E}\right)\right)$ have been computed as below:

$$
\begin{aligned}
& \left(A_{z}\right)=\int_{100}^{P_{s}} \frac{\overline{T^{2}}}{2 \sigma} d p \\
& \left(A_{E}\right)=\int_{100}^{P_{s}} \frac{\overline{T^{2}}}{2 \sigma} d p
\end{aligned}
$$

where $\sigma$ is the static stability parameter of the atmosphere.

$$
\begin{gathered}
K_{Z}=\frac{1}{2 g} \int_{100}^{P_{s}} \overline{\left([u]^{2}+[\nu]^{2}\right)} d p \\
K_{E}=\frac{1}{2 g} \int_{100}^{P_{s}} \overline{\left(u^{\prime 2}+\nu^{\prime 2}\right) d p}
\end{gathered}
$$

$$
\left(C\left(A_{z}, A_{E}\right)\right)=-\int_{100}^{P_{s}}\left[\overline{\frac{1}{\sigma} \nu^{\prime} T^{\prime} \frac{\partial T^{*}}{a \partial \varphi}}+\frac{1}{\sigma} \overline{\omega^{\prime} T^{\prime} \frac{\partial T^{*}}{\partial p}}\right] d p
$$

$$
\left(C\left(K_{z}, K_{E}\right)\right)=\frac{1}{g}\left\{\begin{array}{l}
\int_{100}^{P_{s}}\left[\cos \varphi u^{\prime} \nu^{\prime} \frac{\partial}{a \partial \varphi}\left[\frac{[u]}{\cos \varphi}\right]\right] d p+\int_{100}^{P_{s}} \overline{\left[\nu^{\prime 2} \frac{\partial[\nu]}{a \partial \varphi}\right]} d p+\int_{100}^{P_{s}} \overline{\frac{\tan \varphi}{a} u^{\prime 2}[\nu]} d p \\
+\int_{100}^{P_{s}} \overline{\left[\omega^{\prime} u^{\prime} \frac{\partial[u]}{\partial p}\right]} d p+\int_{100}^{P_{s}} \overline{\left[\omega^{\prime} \nu^{\prime} \frac{\partial[\nu]}{\partial p}\right]} d p
\end{array}\right\}
$$

$$
\left(C\left(A_{E}, K_{E}\right)\right)=-\frac{1}{g} \int_{100}^{P_{s}} \frac{R}{p} \overline{\omega^{\prime} T^{\prime}} d p
$$




$$
G\left(A_{z}\right)=\frac{R_{d}}{C_{p}} \oint \frac{[\theta]^{*}[\dot{Q}]^{*}}{p\left(-\frac{\partial \bar{\theta}}{\partial p}\right)} d m
$$

and

$$
G\left(A_{e}\right)=\frac{R_{d}}{C_{p}} \oint \frac{\theta^{\prime} \dot{Q}^{\prime}}{p\left(-\frac{\partial \bar{\theta}}{\partial p}\right)} d m
$$

\section{Results and discussions}

\subsection{Energetics parameters for JJA season}

Calculated values of energetics parameters for JJA season and ' $t$ ' statistic examining significance in difference in each of 10 energetics parameters of deficient and non-deficient years for the two periods, 1951-1978 and 1979-2005, are shown in tables 1 and 2, respectively. Energetics parameters for September month were not computed due to the fact that the monsoon usually withdraws from the northwestern/northern parts of the country by early September. Similarly, energetics for MAM season and ' $t$ ' statistic examining significance in difference in each of 10 energetics parameters of deficient and non-deficient years for two periods, 1951-1978, and 1979-2005 are shown in tables 3 and 4 , respectively.
It may be observed that, for the period, 19511978, only two energetics parameters out of 10 , viz., the zonal available potential energy (high) and conversion of zonal kinetic energy to eddy kinetic energy (low) differed significantly in JJA season of deficient years from that of non-deficient years.

In the later period 1979-2005, as many as six out of 10 energetics parameters differed significantly. The eddy available potential energy, the zonal available potential energy and the eddy kinetic energy were significantly higher in the deficient years than in the non-deficient years of ISMR in the JJA season, while generation of zonal available potential energy, conversion of zonal available potential energy to zonal kinetic energy and conversion of zonal kinetic energy to eddy kinetic energy were significantly lower in the deficient years than in the non-deficient years.

\subsubsection{Zonal available potential energy}

Zonal available potential energy is associated with the north-south temperature gradient. To examine the same, latitude versus height plot (averaged over the longitudes $40^{\circ}-100^{\circ} \mathrm{E}$ ) for temperature anomaly (composite) for the deficient years of the two periods were prepared and are shown in figure 1. Zonal available potential energy which is significantly higher in deficient years in both the

\begin{tabular}{|c|c|c|c|}
\hline Energetics parameters & Deficient years & Non-deficient years & ' $t$ ' value \\
\hline Eddy available potential energy (Joules $/ \mathrm{cm}^{2}$ ) & $0.7464 \mathrm{E}-01$ & $0.7246 \mathrm{E}-01$ & 1.271 \\
\hline Zonal available potential energy (Joules $/ \mathrm{cm}^{2}$ ) & $0.1053 \mathrm{E}+01$ & $0.1034 \mathrm{E}+01$ & $2.050^{* *}$ \\
\hline Eddy kinetic energy (Joules $/ \mathrm{cm}^{2}$ ) & $0.3106 \mathrm{E}-01$ & $0.2891 \mathrm{E}-01$ & 0.648 \\
\hline Zonal kinetic energy (Joules $/ \mathrm{cm}^{2}$ ) & $0.1873 \mathrm{E}+01$ & $0.2072 \mathrm{E}+01$ & -0.452 \\
\hline Generation of zonal available potential energy (Joules/( $\left.\left.\mathrm{cm}^{2} \mathrm{~s}\right)\right)$ & $-0.1414 \mathrm{E}-06$ & $-0.7331 \mathrm{E}-07$ & -1.596 \\
\hline Generation of eddy available potential energy (Joules/( $\left.\mathrm{cm}^{2} \mathrm{~s}\right)$ ) & $0.7108 \mathrm{E}-07$ & $0.5453 \mathrm{E}-07$ & 0.444 \\
\hline $\begin{array}{l}\text { Conversion of eddy available potential energy } \\
\left.\text { to eddy kinetic energy (Joules } /\left(\mathrm{cm}^{2} \mathrm{~s}\right)\right)\end{array}$ & $0.8532 \mathrm{E}-06$ & $0.6263 \mathrm{E}-06$ & 1.401 \\
\hline $\begin{array}{l}\text { Conversion of zonal available potential energy } \\
\left.\text { to zonal kinetic energy (Joules } /\left(\mathrm{cm}^{2} \mathrm{~s}\right)\right)\end{array}$ & $-0.6284 \mathrm{E}-06$ & $-0.3714 \mathrm{E}-06$ & -1.719 \\
\hline $\begin{array}{l}\text { Conversion of zonal kinetic energy to eddy } \\
\left.\text { kinetic energy (Joules } /\left(\mathrm{cm}^{2} \mathrm{~s}\right)\right)\end{array}$ & $-0.6216 \mathrm{E}-06$ & $-0.2571 \mathrm{E}-06$ & $-2.209^{* *}$ \\
\hline $\begin{array}{l}\text { Conversion of zonal available potential energy } \\
\left.\text { to eddy potential energy (Joules } /\left(\mathrm{cm}^{2} \mathrm{~s}\right)\right)\end{array}$ & $-0.3186 \mathrm{E}-08$ & $-0.4036 \mathrm{E}-08$ & 0.255 \\
\hline
\end{tabular}

Table 1. Energetics parameters during JJA months for 1951-1978.

** Significant at $5 \%$ level. 
Table 2. Energetics parameters during JJA months for 1979-2005.

\begin{tabular}{|c|c|c|c|}
\hline Energetics parameters & Deficient years & Non-deficient years & ' $t$ ' value \\
\hline Eddy available potential energy $\left(\right.$ Joules $\left./ \mathrm{cm}^{2}\right)$ & $0.7698 \mathrm{E}-01$ & $0.7286 \mathrm{E}-01$ & $2.178^{* *}$ \\
\hline Zonal available potential energy (Joules $/ \mathrm{cm}^{2}$ ) & $0.1061 \mathrm{E}+01$ & $0.1030 \mathrm{E}+01$ & $4.170^{* *}$ \\
\hline Eddy kinetic energy (Joules $/ \mathrm{cm}^{2}$ ) & $0.3277 \mathrm{E}-01$ & $0.2506 \mathrm{E}-01$ & $2.391^{* *}$ \\
\hline Zonal kinetic energy (Joules $/ \mathrm{cm}^{2}$ ) & $0.2128 \mathrm{E}+01$ & $0.2063 \mathrm{E}+01$ & 0.152 \\
\hline $\begin{array}{l}\text { Generation of zonal available } \\
\left.\left.\text { potential energy (Joules/( } \mathrm{cm}^{2} \mathrm{~s}\right)\right)\end{array}$ & $-0.1651 \mathrm{E}-06$ & $-0.3437 \mathrm{E}-07$ & $-3.616^{* *}$ \\
\hline $\begin{array}{l}\text { Generation of eddy available } \\
\left.\text { potential energy (Joules } /\left(\mathrm{cm}^{2} \mathrm{~s}\right)\right)\end{array}$ & $0.9653 \mathrm{E}-07$ & $0.4697 \mathrm{E}-07$ & 1.398 \\
\hline $\begin{array}{l}\text { Conversion of eddy available } \\
\text { potential energy to eddy kinetic } \\
\left.\text { energy (Joules } /\left(\mathrm{cm}^{2} \mathrm{~s}\right)\right)\end{array}$ & $0.8361 \mathrm{E}-06$ & $0.6817 \mathrm{E}-06$ & 0.896 \\
\hline $\begin{array}{l}\text { Conversion of zonal available potential energy } \\
\left.\text { to zonal kinetic energy (Joules } /\left(\mathrm{cm}^{2} \mathrm{~s}\right)\right)\end{array}$ & $-0.8511 \mathrm{E}-06$ & $-0.2275 \mathrm{E}-06$ & $-4.339 * *$ \\
\hline $\begin{array}{l}\text { Conversion of zonal kinetic energy } \\
\left.\left.\text { to eddy kinetic energy (Joules/( } \mathrm{cm}^{2} \mathrm{~s}\right)\right)\end{array}$ & $-0.5872 \mathrm{E}-06$ & $-0.6699 \mathrm{E}-07$ & $-3.107^{* *}$ \\
\hline $\begin{array}{l}\text { Conversion of zonal available potential energy } \\
\left.\text { to eddy potential energy (Joules } /\left(\mathrm{cm}^{2} \mathrm{~s}\right)\right)\end{array}$ & $-0.4776 \mathrm{E}-08$ & $-0.2592 \mathrm{E}-08$ & -0.941 \\
\hline
\end{tabular}

**Significant at $5 \%$ level.

periods, may be due to the anomalous north-south gradient observed in the latitude versus temperature (composite) anomaly height plots. Usually, in the extratropics, temperature gradient is from the south to the north. But in the deficient years, latitude belt around $30^{\circ} \mathrm{N}$ is anomalously cool while latitude belt around $50^{\circ} \mathrm{N}$ is anomalously warm (as noticed in figure 1). This establishes an anomalous north-south temperature gradient and due to this, actual south to north temperature gradient is reduced. This may cause zonal flow of middle latitude to become relatively weak to allow transient waves in the mean flow to reach much south. Rajeevan et al. (1998) attributed this reduced south north temperature gradient for weaker zonal flow in the middle latitudes. It may be further observed that this anomalous north-south gradient is more than twice in the deficient years of later period, which suggests a more prominent role of mid-latitude circulation in weakening monsoon circulation and subsequently causing deficient ISMR in recent years.

Further, we examined difference in the tropospheric temperature of the deficient years of the period 1979-2005 and that of the 1951-1978 period. Latitude versus height plot (averaged over the longitudes $40^{\circ}-100^{\circ} \mathrm{E}$ ) for temperature difference (average temperature of deficient years of the period 1979-2005, minus average temperature of deficient years of the period 1951-1978) is prepared and is shown in figure 3(a). This figure indicates that the whole troposphere around $35^{\circ} \mathrm{N}$ (with northward tilt) is much cooler (negative difference) in the deficient years of the period 19792005. This additional cooling was responsible for strong anomalous north-south temperature gradient and probably due to this the zonal available potential energy in the deficient years of 1979-2005 period was more than that of 1951-1980 period.

\subsubsection{Eddy available potential energy}

Eddy available potential energy is linked to eastwest temperature gradient. Therefore, east-west temperature gradient was examined by preparing the composite longitude versus height plots (averaged over the latitudes $35^{\circ}-55^{\circ} \mathrm{N}$ ) for temperature anomaly for the deficient years of both the periods. These results are shown in figure 2 . It may be seen that an east-west temperature gradient existed in the composite temperature 
Table 3. Energetics parameters during MAM months for 1951-1978.

\begin{tabular}{|c|c|c|c|}
\hline Energetics parameters & Deficient years & Non-deficient years & ' $t$ ' value \\
\hline Eddy available potential energy (Joules $/ \mathrm{cm}^{2}$ ) & $0.1221 \mathrm{E}+00$ & $0.1220 \mathrm{E}+00$ & 0.046 \\
\hline Zonal available potential energy (Joules $/ \mathrm{cm}^{2}$ ) & $0.1046 \mathrm{E}+01$ & $0.1050 \mathrm{E}+01$ & -0.696 \\
\hline Eddy kinetic energy (Joules/cm²) & $0.3033 \mathrm{E}-01$ & $0.2719 \mathrm{E}-01$ & 0.829 \\
\hline Zonal kinetic energy (Joules $/ \mathrm{cm}^{2}$ ) & $0.2402 \mathrm{E}+01$ & $0.2493 \mathrm{E}+01$ & -0.181 \\
\hline $\begin{array}{l}\text { Generation of zonal available } \\
\text { potential energy (Joules } /\left(\mathrm{cm}^{2} \mathrm{~s}\right)\end{array}$ & $0.6682 \mathrm{E}-07$ & $0.4647 \mathrm{E}-07$ & 0.445 \\
\hline $\begin{array}{l}\text { Generation of eddy available } \\
\text { potential energy (Joules } /\left(\mathrm{cm}^{2} \mathrm{~s}\right)\end{array}$ & $0.1350 \mathrm{E}-06$ & $0.9288 \mathrm{E}-07$ & 0.874 \\
\hline $\begin{array}{l}\text { Conversion of eddy available potential energy } \\
\text { to eddy kinetic energy (Joules } /\left(\mathrm{cm}^{2} \mathrm{~s}\right)\end{array}$ & $0.7689 \mathrm{E}-06$ & $0.4316 \mathrm{E}-06$ & $2.711^{* *}$ \\
\hline $\begin{array}{l}\text { Conversion of zonal available potential energy } \\
\text { to zonal kinetic energy (Joules } /\left(\mathrm{cm}^{2} \mathrm{~s}\right)\end{array}$ & $0.1430 \mathrm{E}-06$ & $-0.8754 \mathrm{E}-07$ & 1.274 \\
\hline $\begin{array}{l}\text { Conversion of zonal kinetic energy } \\
\left.\text { to eddy kinetic energy (Joules/( } \mathrm{cm}^{2} \mathrm{~s}\right)\end{array}$ & $0.3781 \mathrm{E}-06$ & $0.2074 \mathrm{E}-06$ & 1.221 \\
\hline $\begin{array}{l}\text { Conversion of zonal available potential energy } \\
\text { to eddy potential energy (Joules } /\left(\mathrm{cm}^{2} \mathrm{~s}\right)\end{array}$ & $0.3106 \mathrm{E}-08$ & $-0.4428 \mathrm{E}-09$ & 0.484 \\
\hline
\end{tabular}

** Significant at $5 \%$ level.

Table 4. Energetics parameters during MAM months for 1979-2005.

\begin{tabular}{|c|c|c|c|}
\hline Energetics parameters & Deficient years & Non-deficient years & 't' value \\
\hline Eddy available potential energy (Joules $/ \mathrm{cm}^{2}$ ) & $1.24 \mathrm{E}-01$ & $1.23 \mathrm{E}-01$ & 0.554 \\
\hline Zonal available potential energy (Joules $/ \mathrm{cm}^{2}$ ) & $1.04 \mathrm{E}+00$ & $1.05 \mathrm{E}+00$ & -1.399 \\
\hline Eddy kinetic energy (Joules $/ \mathrm{cm}^{2}$ ) & $3.77 \mathrm{E}-02$ & $2.53 \mathrm{E}-02$ & $3.216^{* *}$ \\
\hline Zonal kinetic energy (Joules $/ \mathrm{cm}^{2}$ ) & $3.04 \mathrm{E}+00$ & $2.42 \mathrm{E}+00$ & 1.203 \\
\hline $\begin{array}{l}\text { Generation of zonal available } \\
\text { potential energy (Joules } /\left(\mathrm{cm}^{2} \mathrm{~s}\right)\end{array}$ & $9.89 \mathrm{E}-08$ & $3.46 \mathrm{E}-08$ & 1.235 \\
\hline $\begin{array}{l}\text { Generation of eddy available } \\
\text { potential energy (Joules } /\left(\mathrm{cm}^{2} \mathrm{~s}\right)\end{array}$ & $1.64 \mathrm{E}-07$ & $3.37 \mathrm{E}-08$ & $2.218^{* *}$ \\
\hline $\begin{array}{l}\text { Conversion of eddy available potential energy } \\
\text { to eddy kinetic energy (Joules } /\left(\mathrm{cm}^{2} \mathrm{~s}\right)\end{array}$ & $7.23 \mathrm{E}-07$ & $3.64 \mathrm{E}-07$ & $3.167^{* *}$ \\
\hline $\begin{array}{l}\text { Conversion of zonal available potential energy } \\
\text { to zonal kinetic energy (Joules } /\left(\mathrm{cm}^{2} \mathrm{~s}\right)\end{array}$ & $7.85 \mathrm{E}-08$ & $-2.26 \mathrm{E}-07$ & 1.668 \\
\hline $\begin{array}{l}\text { Conversion of zonal kinetic energy } \\
\text { to eddy kinetic energy (Joules } /\left(\mathrm{cm}^{2} \mathrm{~s}\right)\end{array}$ & $8.41 \mathrm{E}-07$ & $4.58 \mathrm{E}-07$ & $2.425^{* *}$ \\
\hline $\begin{array}{l}\text { Conversion of zonal available potential energy } \\
\text { to eddy potential energy (Joules } /\left(\mathrm{cm}^{2} \mathrm{~s}\right)\end{array}$ & $4.27 \mathrm{E}-09$ & $1.26 \mathrm{E}-09$ & 0.519 \\
\hline
\end{tabular}

** Significant at $5 \%$ level. 


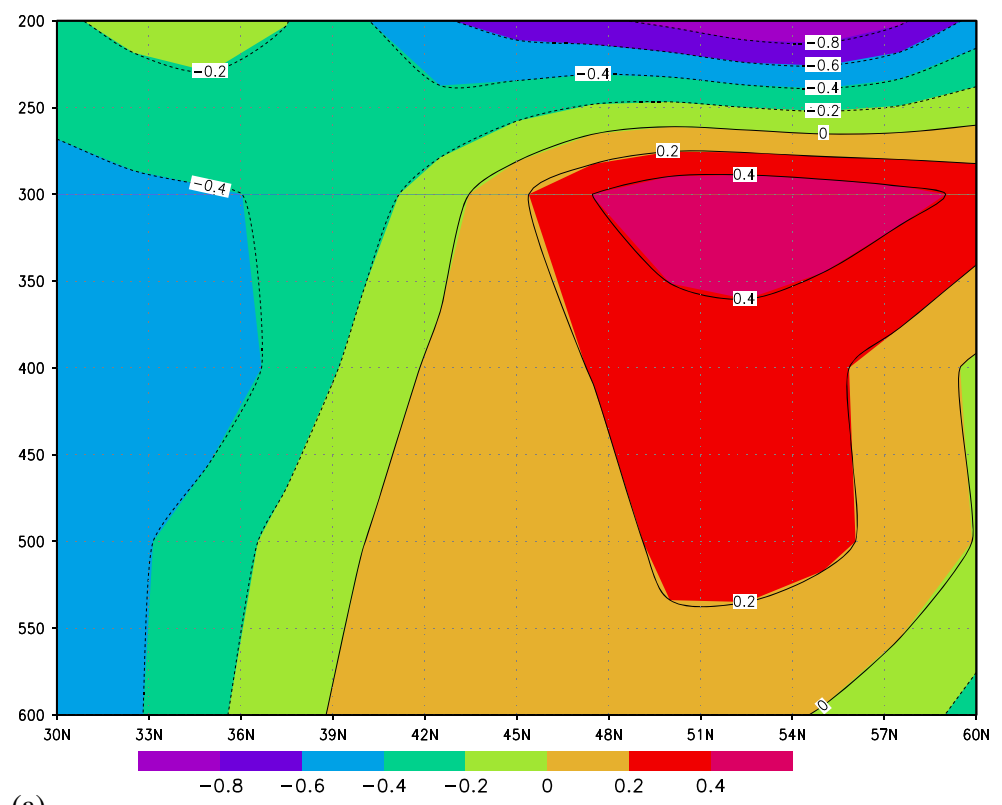

(a)

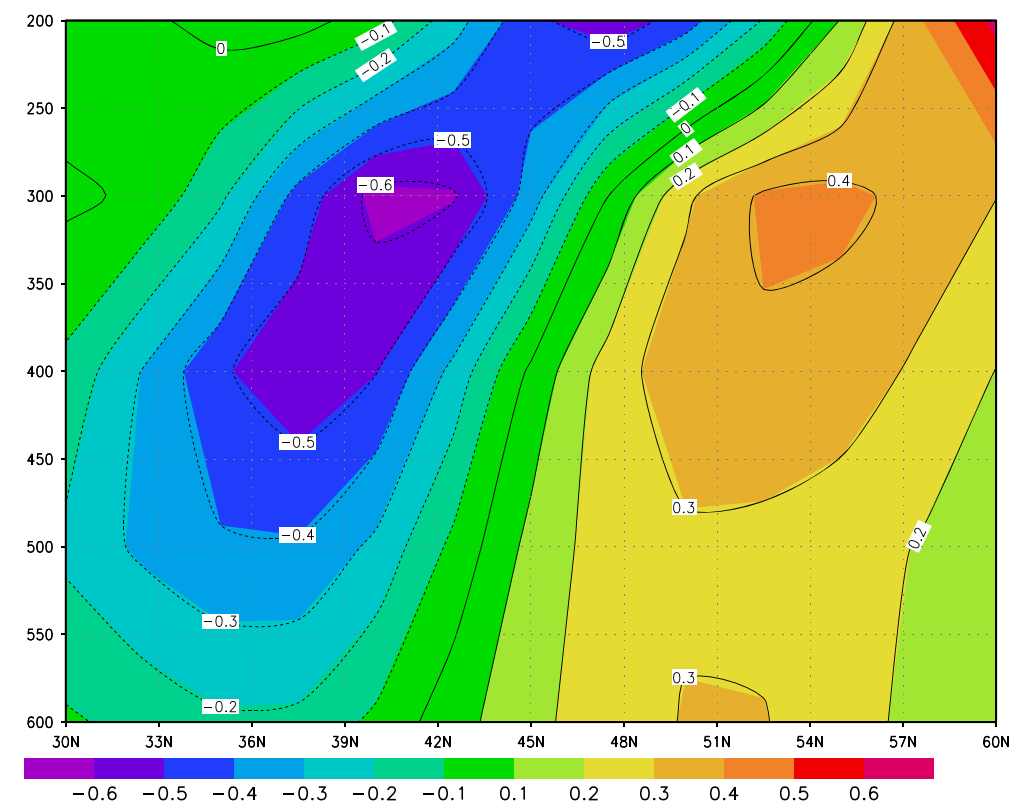

(b)

Figure 1. Latitude versus temperature (composite) anomaly height plot, averaged over the longitudes $40^{\circ}-100^{\circ} \mathrm{E}$ for the deficient years of (a) 1951-1978 and (b) 1979-2005.

anomaly plots of deficient years of both the periods. However, this parameter was found to be significantly higher only in the deficient years than in the non-deficient years of the later period 1979-2005. However, same though being relatively more in deficient years of the 1951-1978 period, than in non-deficient years did not differ significantly. To examine the probable cause, difference in the tropospheric temperature of deficient years of the period 1979-2005 and that of the period 1951-1978 is analyzed. Longitude versus height plot (averaged over the latitudes $35^{\circ}-55^{\circ} \mathrm{N}$ ) for temperature difference (average temperature of deficient years of the period 19792005, minus average temperature of deficient years of the period 1951-1978) is prepared and is shown in figure 3(b). This figure reveals the presence of more anomalous east-west temperature gradient in the deficient years of the later period and therefore, the eddy available potential energy in the deficient years of 1979-2005 was significantly higher than in the non-deficient years of the same period. Same though, being relatively more in deficient years of the 1951-1978 period, than in non-deficient years did not differ significantly. 


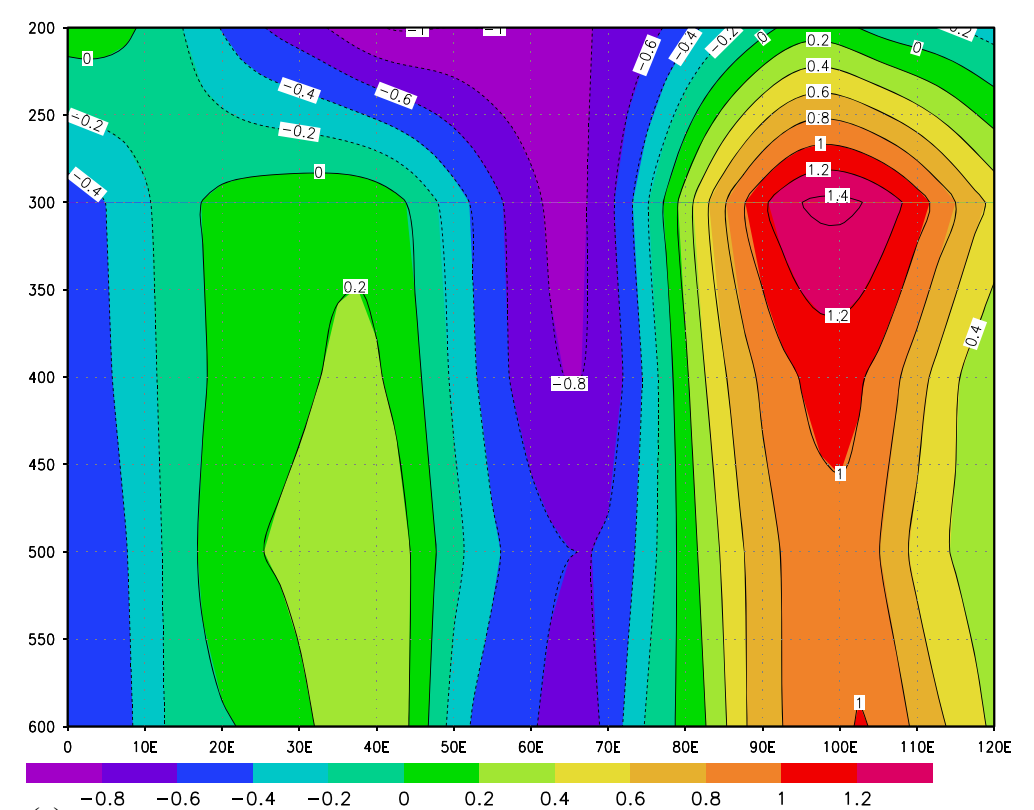

(a)

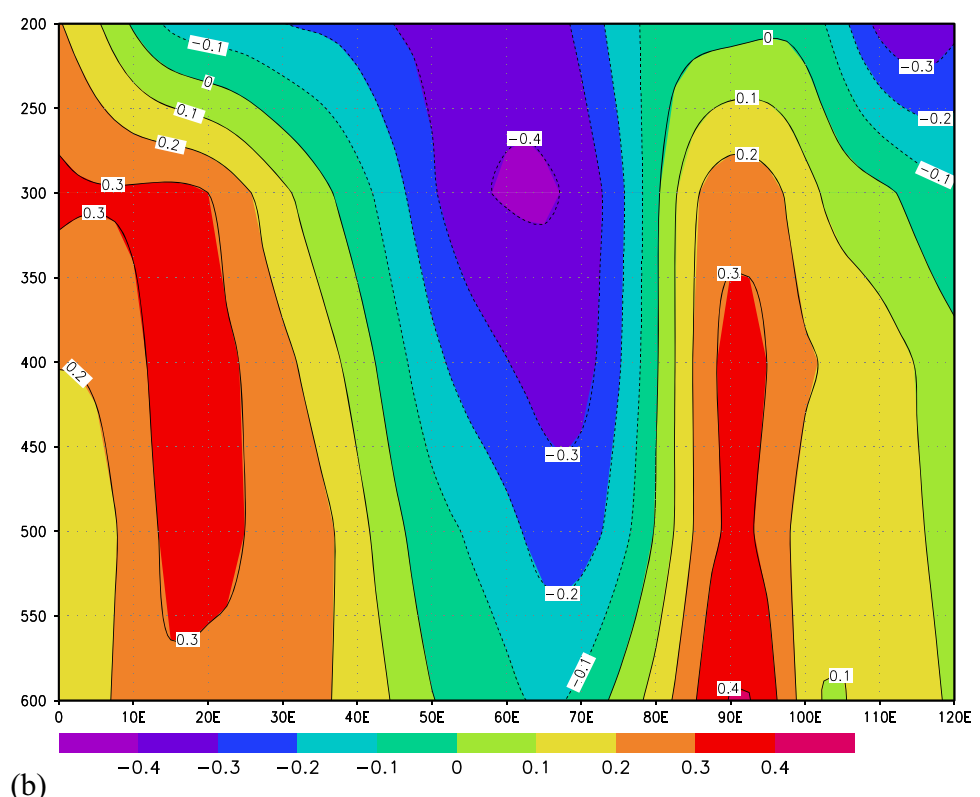

Figure 2. Longitude versus temperature (composite) anomaly height plot, averaged over the latitudes $35^{\circ}-55^{\circ} \mathrm{N}$, for the deficient years of (a) 1951-1978 and (b) 1979-2005.

\subsubsection{Generation of zonal available potential energy}

Generation of zonal available potential energy $\left[G\left(A_{Z}\right)\right]$ which is dependent (positive) on heating of warm and cooling of the cold region, is usually negative in the extratropics. Eastward propagating transient waves in the mean zonal flow bring cold air from higher latitudes to lower latitudes and carry warm air of the lower latitudes to the higher latitudes and thus are apparently responsible for the dissipation of zonal available potential energy. Troughs of these waves pass through the lower latitudes (warm region) and ridges of these waves pass through the higher latitudes (cold region). Winds in the waves carry colder air to the trough region (warm area) and take warm air to the higher latitudes (cold region). This appears to be the apparent reason due to which $G\left(A_{Z}\right)$ is generally negative both in the deficient and non-deficient years. More wave activity would imply more negative $G\left(A_{Z}\right)$. This parameter was significantly lower in the deficient years of the 1979-2005 period than in non-deficient years of the same period. This also suggests more transient waves in the deficient years of 1979-2005 period. 


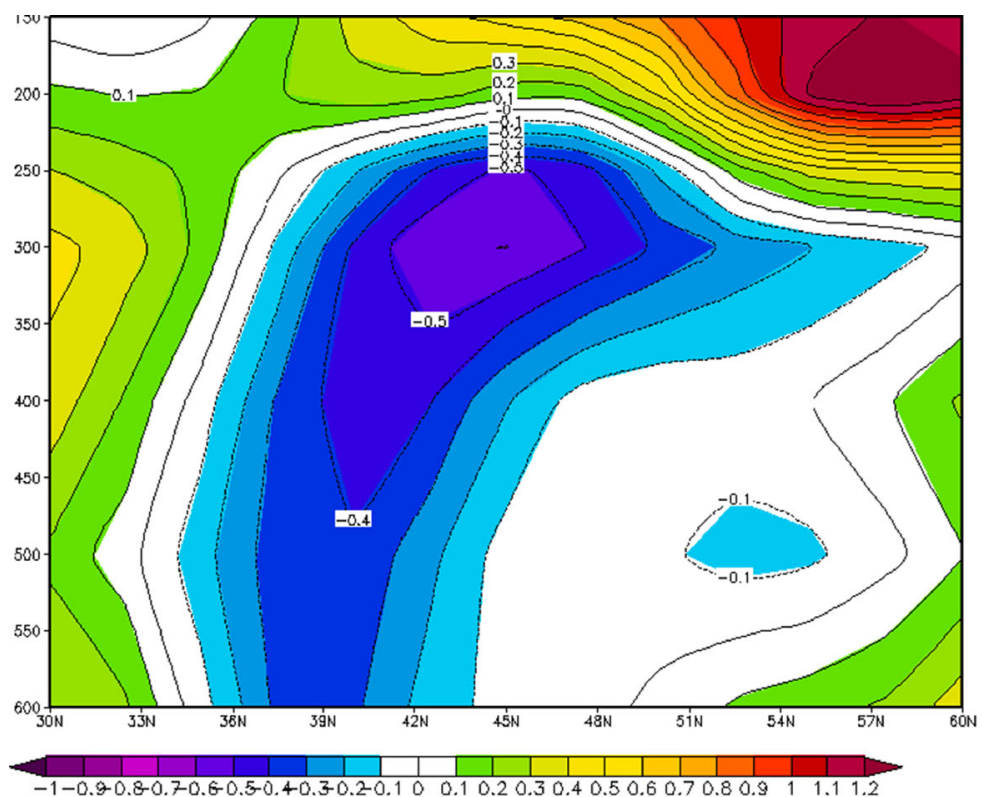

(a)

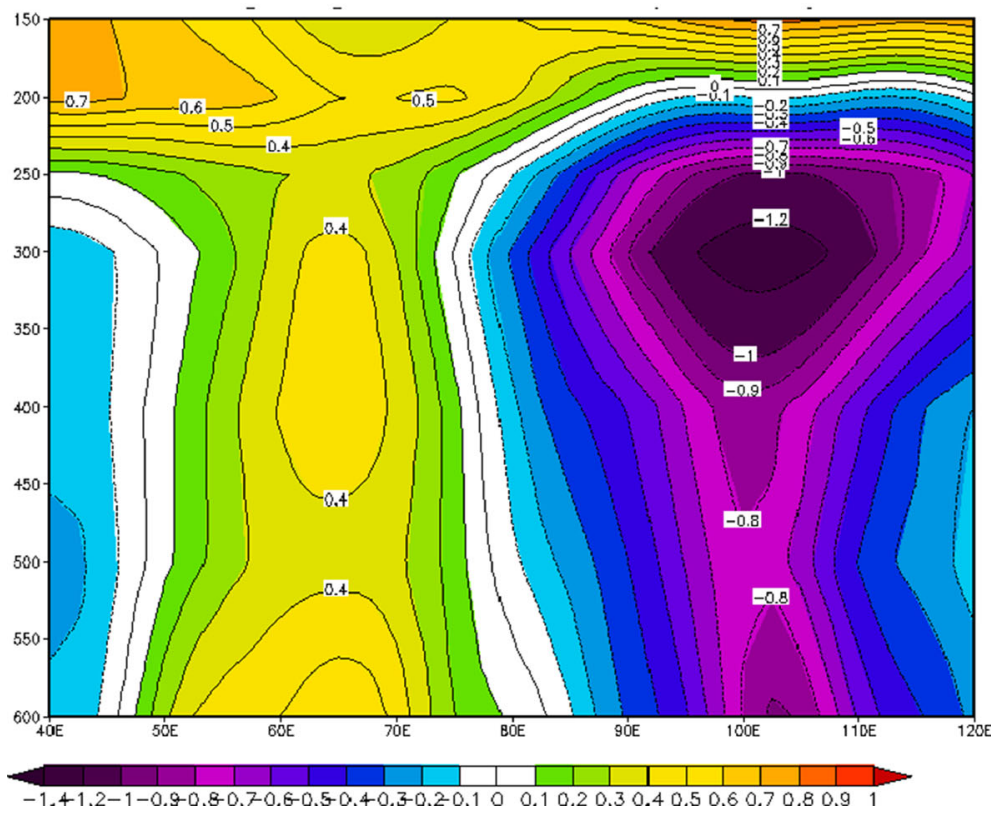

(b)

Figure 3. (a) Latitude versus height temperature (difference) plot (averaged over the longitudes $40^{\circ}-100^{\circ} \mathrm{E}$ ) and (b) longitude versus height temperature (difference) anomaly plot (averaged over the latitudes $35^{\circ}-55^{\circ} \mathrm{N}$ ).

\subsubsection{Conversion of zonal available potential energy to the zonal kinetic energy}

Now, we discuss conversion of the zonal available potential energy to zonal kinetic energy. From its expression, it is clear that this term will be positive if rising motion takes place over relatively warmer southern latitude and sinking motion over relatively colder northern latitudinal belts, i.e., if there is a thermally direct circulation in the meridional vertical plane. It may be seen that the term is negative in both the deficient and non-deficient years, which may be attributed to the thermally indirect circulation due to sinking motion over the belt of subtropical anticyclone and rising motion over the belt of subpolar low. This term was significantly lower in the deficient years of the period 1979-2005. It may be inferred that the zonal flow also slowed down significantly in the deficient years in the middle latitude between longitudes $40^{\circ} \mathrm{E}$ and $100^{\circ} \mathrm{E}$, compared to the non-deficient years of the period, leading to a low zonal index situation with comparatively more mid-latitude wave activities. Similar tendency could be observed for the 
deficient and non-deficient years of 1951-1978 period but difference between the two was not statistically significant.

\subsubsection{Conversion of zonal kinetic energy to the eddy kinetic energy}

Finally, we discuss the conversion of zonal kinetic energy to eddy kinetic energy. Conversion of zonal kinetic energy to the eddy kinetic energy is found to be significantly lower in the deficient to nondeficient years in both the periods. It may be mentioned that in both the deficient and non-deficient years, this conversion is negative. This suggests that movement of eddies is rather slow or in other words, these stagnate and become stationary between $40^{\circ} \mathrm{E}$ and $100^{\circ} \mathrm{E}$, more in deficient years. As such kinetic energy of eddies is being transferred to the zonal kinetic energy as a feedback mechanism. It may be mentioned here that several studies highlighted presence of such waves in drought years.

Thus, for JJA months, more energetics parameters (six) differed significantly in the deficient and non-deficient years of the 1979-2005 than energetics parameters (only two) in the deficient and nondeficient years of the 1951-1978. This again highlights increasing influence of the extratropics in modulating the ISMR in recent years.

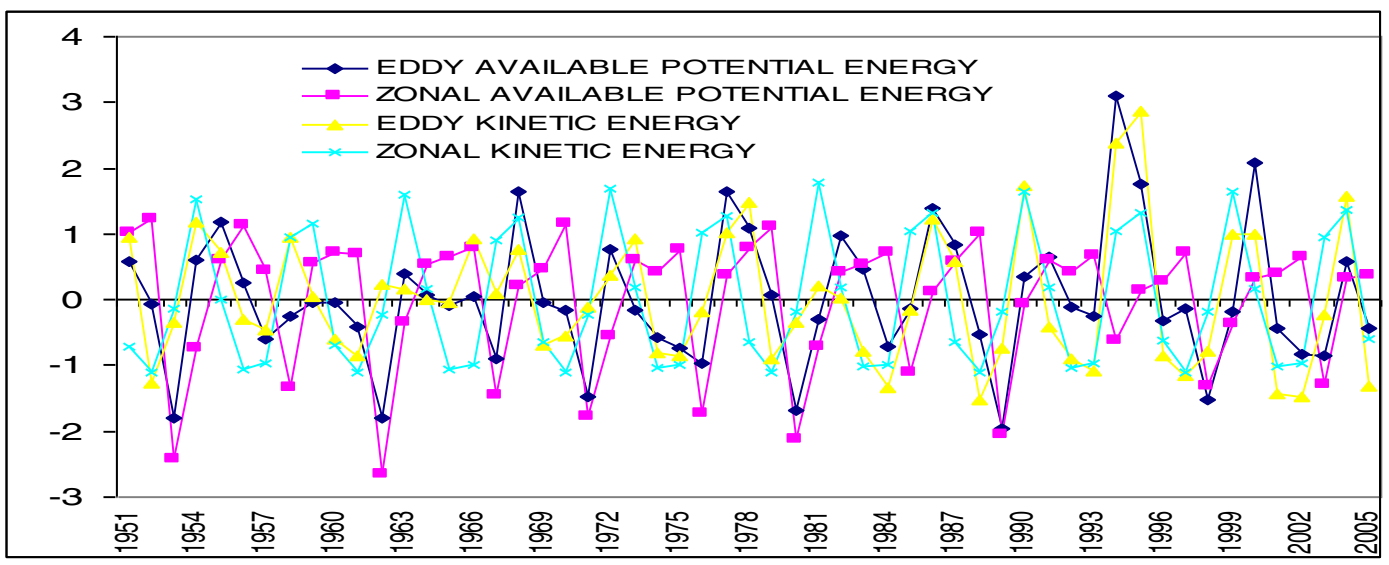

(a)

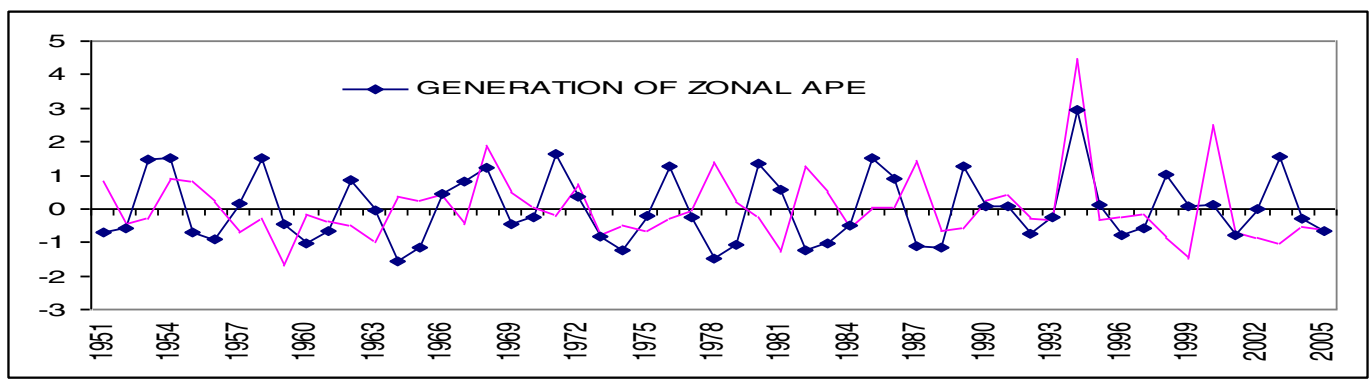

(b)

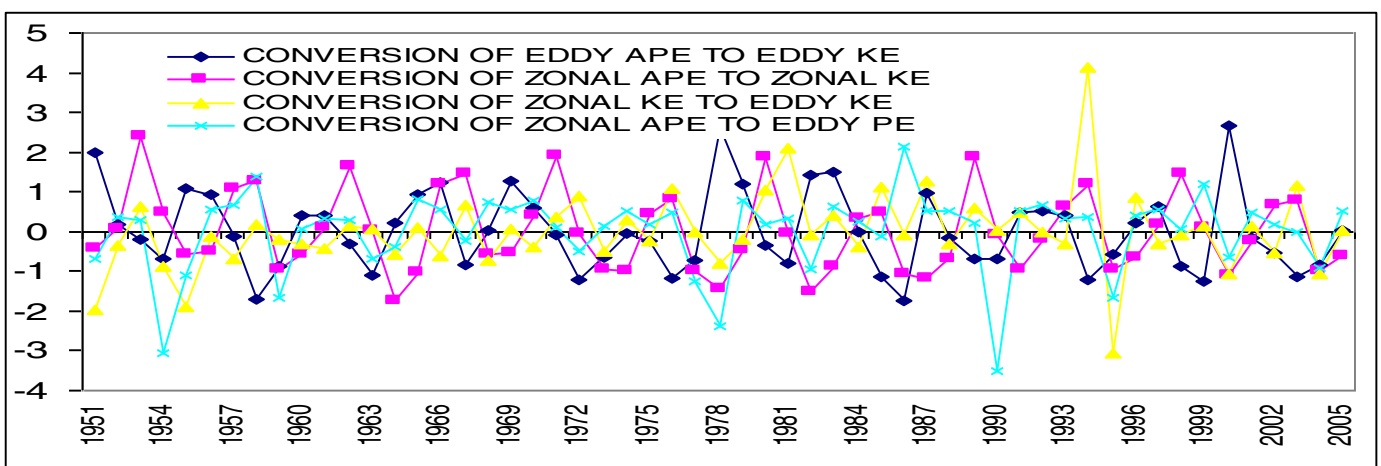

(c)

Figure 4. Standardized time series of 10 energetics parameters (a) EAPE, ZAPE, EKE, ZKE, (b) generation of APE, generation of EPE, and (c) the four conversion term. 
We have shown standardized time series of the 10 energetics parameters in figure 4 .

\subsection{Energetics parameters for MAM season}

We also examined energetics parameters in the MAM season of the same region to find out whether any of above signal was present before ensuing monsoon season or not. We did similar exercise for the deficient and the non-deficient years of both the periods 1951-1978, 1979-2005 and tested significance of the difference between values of the energetics parameters of the deficient and non-deficient years.

These results are shown in tables 3 and 4 . We observe that only one energetic parameter (conversion of eddy available potential energy to the eddy kinetic energy) differed significantly in the deficient than in the non-deficient years of the former period 1951-1978. However, for the later period (19792005), four energetics parameters, viz., (1) the eddy kinetic energy, (2) generation of eddy available potential energy, (3) conversion of the eddy available potential energy to the eddy kinetic energy and (4) conversion of the zonal kinetic energy to the eddy kinetic energy, differed significantly than in the non-deficient years. This clearly spells that signature of above normal transient waves was present in the MAM months (prior to the summer monsoon season) of the deficient years of recent years.

\section{Conclusions}

Energetics parameters for deficient and nondeficient years of the periods 1951-1978 and 19792005 are computed and studied for both monsoon and pre-monsoon months. It is found that, in the JJA months of the later period, viz., 1979-2005, as many as six out of 10 energetics parameters differed significantly in JJA months from that of the non-deficient years. The eddy available potential energy, the zonal available potential energy and the eddy kinetic energy were significantly higher in the deficient years than in the non-deficient years of ISMR, while generation of zonal available potential energy, conversion of zonal available potential energy to zonal kinetic energy and conversion of zonal kinetic energy to eddy kinetic energy were significantly lower in the deficient years than in the non-deficient years. It was further found that only two energetics parameters out of the 10, viz., the zonal available potential energy (high) and conversion of zonal kinetic energy to eddy kinetic energy (low) differed significantly in JJA months of deficient years from that of non-deficient years of the period 1951-1978. It may be attributed to the more anomalous north-south and east-west temperature gradients in the deficient years of the later period and more slow moving transient waves. Energetics parameters for MAM months for the deficient years of the later period also revealed that extratropics was more favourable for the transient waves activities. This clearly suggests that extratropics is playing a greater role in influencing the ISMR in recent years.

\section{Acknowledgements}

Authors are grateful to the DGM, IMD for providing necessary facilities for the study. They are thankful to Shri S Krishnaiah, ADGM(R) and Shri B Mukhopadhyay, DDGM(C) for providing constant encouragement. Thanks are also due to Smt. U J D'souza for typing the manuscript.

\section{References}

Barnett T P 1983 Interaction of the monsoon and Pacific trade wind system at inter annual time scales. Part I: The equatorial zone; Mon. Wea. Rev. 111(4) 756-773.

Bjerknes J 1969 Atmospheric teleconnections from the equatorial Pacific; Mon. Wea. Rev. 97 163-172.

Branstator G 2002 Circumglobal teleconnections, the jet stream wave guide and the north Atlantic Oscillation; J. Climate 15 1893-1910.

Chang C P, Harr P and Ju J 2001 Possible role of Atlantic circulations on the weakening Indian monsoon rainfall ENSO relationship; J. Climate 14 2376-2380.

Ding Q and Wang B 2005 Circimglobal teleconnection in the Northern Hemisphere summer; J. Climate 18 3483-3505.

Ding Q and Wang B 2007 Intra-seasonal teleconnection between the summer Eurasian wave train and the Indian monsoon; J. Climate 20 3571-3767.

Dutta S, Narkhedkar S G, Devi S and Sikka D R 2012 A composite energetics study for contrasting southwest monsoon years in the recent decade; Atmosfera 25(2) $109-126$.

Goswami B N, Madhusoodanan M S, Neema C P and Sengupta D 2006 A physical mechanism for North Atlantic SST influence on the Indian summer monsoon; Geophys. Res. Lett. 33 L02706, doi: 10.1029/2005GL024803.

Hoskins B J and Ambrizzi T 1993 Rossby wave propagation on a realistic longitudinally varying flow; J. Atmos. Sci. 50 1661-1671.

Kane R P 2005 Unstable ENSO relationship with Indian regional rainfall; Int. J. Climatol. 26(6) 771-783.

Keshavamurty R N 1982 Response of the atmosphere to sea surface temperature anomalies over the equatorial Pacific and the teleconnections of the southern oscillation; J. Atmos. Sci. 39 1241-1259.

Kripalani R H, Kulkarni A and Singh S V 1997 Association of the ISM with the NH mid-latitude circulation; Int. J. Climatol. 17 1055-1067.

Krishnamurthy V and Goswami B N 2000 Indian monsoonENSO relationship on inter decadal time scales; J. Climate 13 579-595.

Krishnamurty T N and Bounoua L 2000 An introduction to numerical weather prediction techniques; CRC Press Inc., pp. $1-286$. 
Krishna Kumar K, Rajagopalan B and Cane M A 1999 On the weakening relationship between the Indian monsoon and ENSO; Science 284 2156-2159.

Krishna Kumar K, Rajagopalan B, Hoerling M, Bates G and Cane M 2006 Unravelling the mystery of indian monsoon failure during El Nino; Science, doi: 10.1126/science.1131152.

Krishnan R, Kumar Vinay, Sugi M and Yoshimura J 2009 Internal feedback from monsoon-midlatitude interactions during droughts in the Indian summer monsson; $A m$. Meteorol. Soc. 66 553-578.

Li S, Perlwitz J, Quan X and Hoerling M P 2008 Modelling influence of North Atlantic multidecadal warmth on the Indian summer rainfall; Geophys. Res. Lett. 35 L05804, doi: 10.1029/2007GL032901.

Mooley D A and Parthasarathy B 1984 Indian summer monsoon and east equatorial Pacific SST; Atmos. Ocean 22 23-35.

Pai D S 2004 A possible mechanism for the weakening of El-Nino monsoon relationship during recent decades; Meteorol. Atmos. Phys. 86 143-157.

Pant G B and Parthasarathy B 1981 Some aspects of the association between southern oscillation and Indian summer monsoon, Arch; Meteorol. Geophys. Book 229 245-252.

Rajeevan M, Pai D S and Thapliyal V 1998 Spatial and temporal relationships between global and surface air temperature anomalies and Indian summer monsoon; Meteorol. Atmos. Phys. 66 157-171.

Rajeevan M and Pai D S 2007 On the El Nino-Indian monsoon predictive relationships, 2007; Geophys. Res. Lett. 34, doi: 10.1029/2006GL028916.
Raman C R V and Rao Y P 1981 Blocking highs over Asia and droughts over India; Nature 289 271273.

Rasmusson E M and Carpenter T H 1982 Variation in tropical sea surface temperature and surface wind fields associated with southern oscillation/El Nino; Mon. Wea. Rev. $110354-384$.

Rasmusson E M and Carpenter T H 1983 The relationship between eastern equatorial Pacific sea surface temperature and rainfall over India and Sri Lanka; Mon. Wea. Rev. 111 517-528.

Sikka D R 1980 Some aspects of the large scale fluctuations of summer monsoon rainfall over India in relation to fluctuations in the planetary and regional scale circulation parameters; Proc. Indian Acad. Sci. (Earth Planet. Sci.) 89 179-195.

Srivastava A K, Rajeevan M and Kulkarni R 2002 Teleconnection of OLR and SST anomalies over Atlantic Ocean with Indian summer monsoon; Geophys. Res. Lett. 29(8) 125-1-125-4.

Srivastava A K, Guhathakurta P, Rajeevan M, Dikshit S K and Kshirsagar S R 2007 Did unusual warming over the mid and higher latitudes cause unprecedented failure of southwest monsoon during July 2002? Meteorol. Atmos. Phys. 96(3-4) 193-201.

Walker G T 1924 Correlation in seasonal variations of weather. IV. A further study of world weather; India Meteorol. Dept. Memoir 24 275-332.

Webster P J and Yang S 1992 Monsoon and ENSO: Selectively interactive systems; Quart. J. Roy. Meteorol. Soc. 118 877-926. 